\title{
Improving genetic diagnostics of skeletal muscle channelopathies
}

\begin{abstract}
Introduction: Skeletal muscle channelopathies are rare inherited conditions that cause significant morbidity and impact on quality of life. Some subsets have a mortality risk. Improved genetic methodology and understanding of phenotypes has improved diagnostic accuracy and yield.

Areas covered: We discuss diagnostic advances since the advent of next generation sequencing and the role of whole exome and genome sequencing. Advances in genotype-phenotype-functional correlations have improved understanding of inheritance and phenotypes. We outline new phenotypes, particularly in the paediatric setting and consider co-existing mutations that may act as genetic modifiers. We also discuss four newly identified genes associated with skeletal muscle channelopathies.

Expert Opinion/Commentary: Next generation sequencing using gene panels has improved diagnostic rates, identified new mutations and discovered patients with co-existing pathogenic mutations ("double trouble"). This field has previously focussed on single genes, but we are now beginning to understand interactions between co-existing mutations, genetic modifiers and their role in pathomechanisms. New genetic observations in paediatric presentations of channelopathies broadens our understanding of the conditions. Genetic and mechanistic advances have increased potential to develop treatments.
\end{abstract}

Keywords: channelopathies, chloride channel, muscle, myotonia, periodic paralysis, sodium channel

\section{Article Highlights:}

- Next generation sequencing has advanced genetic diagnostics

- Some CLCN1 mutations may have dominant or recessive inheritance in different pedigrees

- Co-existing pathogenic mutations in skeletal muscle channelopathies may occur, parallel sequencing (as in next generations sequencing) is important to detect these

- Co-existing mutations may modify the phenotype

- Paediatric presentations of channelopathies are important to recognise

\section{Introduction to Skeletal Muscle Channelopathies}

The skeletal muscle channelopathies are a rare group of genetic conditions that typically cause episodic symptoms. Our prevalence study in England in 2013, described a minimum point prevalence of 1.2/100 000(1). In a 2019 audit of our national clinical service, we identified an increased minimum point prevalence rate of $2.32 / 100000$. The changing prevalence estimates are mainly due to improved genetic diagnostics, including methodology, and improved understanding of broader phenotypes and genotype-phenotype-functional correlation, which we describe here.

The classical muscle channelopathies cause conditions across a spectrum of symptoms from myotonia (delayed muscle relaxation after contraction) to paralysis, figure 1. Myotonia occurs as a result of muscle membrane hyperexcitability and is experienced as stiffness, cramps, falls and 
muscle hypertrophy(2). Myotonia can affect all skeletal muscle including face, tongue and intercostal muscle. Paralysis reflects inexcitability of the muscle membrane resulting in weakness(3). With the increasing availability of genetic data, ion channel variants have also recently been described in patients with diagnoses such as congenital myopathy and myasthenia as well as sudden infant death.

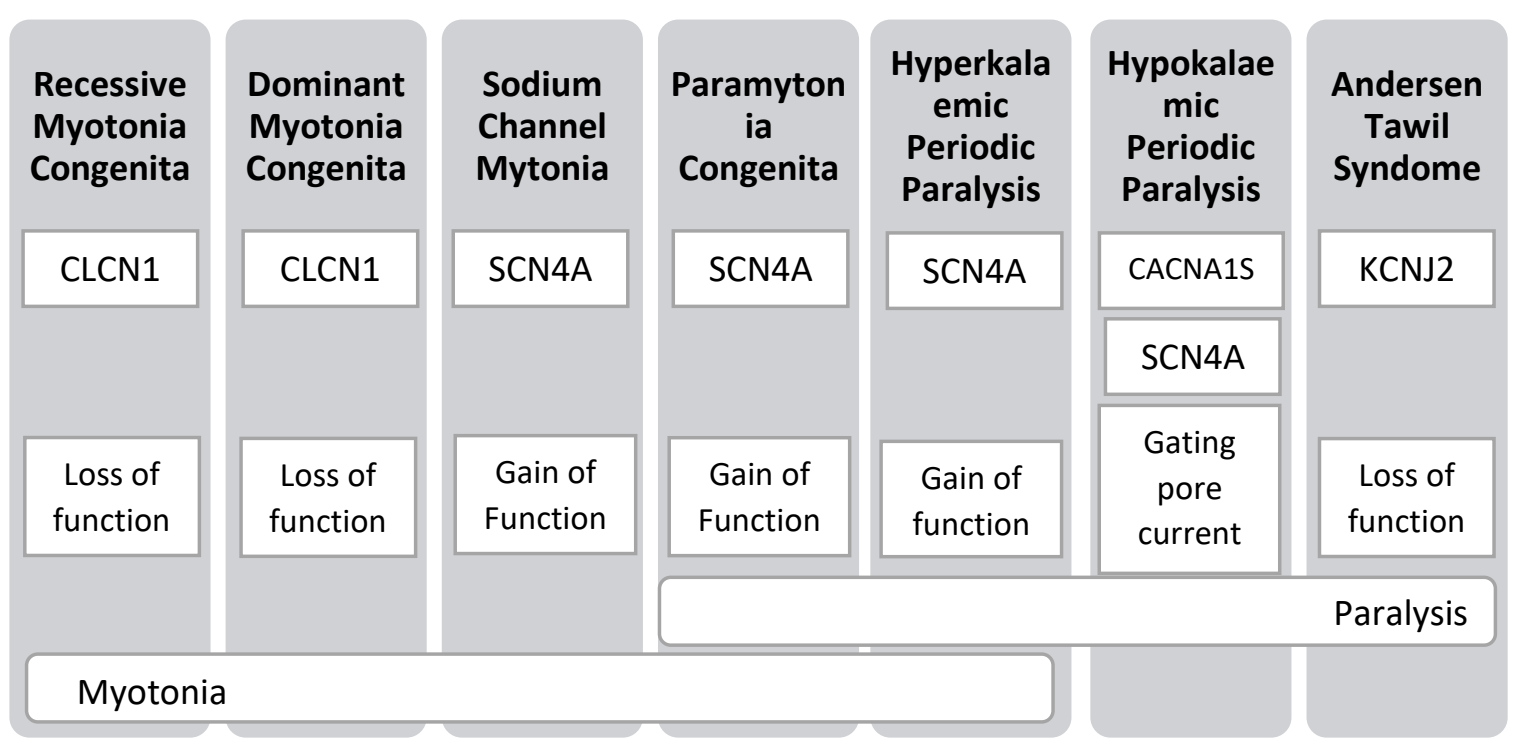

Figure 1: The spectrum of skeletal muscle channelopathies; implicated genes and resultant effect on the channel.

\subsection{Myotonia Congenita}

Myotonia Congenita (MC) is the most common skeletal muscle channelopathy. It is caused by mutations in the CLCN1 gene, which encodes the voltage-gated chloride channel ClC-1. The functional channel protein is comprised of two gene products (4). The symptoms of myotonia generally present in the first or second decade of life(5). Symptoms of myotonia are prominent at the initiation of movement and often improve with repeated activity - a phenomenon known as 'warm up'. Patients with recessively inherited myotonia congenita tend to have more severe symptoms compared to patients with dominant mutations (4) and additionally, some patients with recessive $\mathrm{MC}$ have transient weakness at initiation of movement. Hundreds of pathogenic mutations have been identified in CLCN1, the majority of CLCN1 mutations are missense with Gly230Glu the most common(1,6).

\subsection{Paramyotonia Congenita and Sodium Channel Myotonia}

Paramyotonia congenita (PMC) and Sodium channel myotonia (SCM) are caused by mutations in the SCN4A gene encoding the alpha sub-unit of the voltage gated sodium channel, Nav1.4. The mutant channels show a gain of channel function on heterologous expression(7). Both conditions are inherited in a dominant fashion. Patients with paramyotonia congenita can be particularly sensitive to cold and have 'paradoxical warm-up' phenomenon where myotonia worsens with repeated 
contraction(8). They may also have episodic muscle weakness or paralysis. This episodic weakness is not seen in Sodium Channel Myotonia(9).

\subsection{Periodic Paralyses}

Three conditions constitute the periodic paralyses. Hyperkalaemic periodic paralysis (HyperPP) is caused by mutations in the SCN4A gene, and like in SCM and PMC, the mutations increase the function of the mutant channel. Patients develop episodic weakness associated with high serum potassium levels. Attacks of paralysis typically last from minutes to hours and can be triggered by cold and rest after exercise(10). Myotonia can also be present (figure1), sometimes clinically and, at times only on electromyography (EMG)(11).

Hypokalaemic periodic paralysis (HypoPP) patients present with attacks of paralysis associated with low serum potassium. Attacks often last longer, hours to days, and are triggered by carbohydrate rich food and exercise(12). The majority (up to $88 \%$ ) are caused by mutations in the CACNA1S gene encoding the muscle voltage sensing calcium channel, Cav1.1, with the rest caused by SCN4A mutations(10). Mutations in both genes cluster in the regions encoding the channel S4 voltage sensing domains and cause a 'gating pore leak current' - an aberrant leak current - leading to paralysis(13).

The third disorder in the group of periodic paralyses is Andersen-Tawil Syndrome (ATS) which is caused by mutations in the KCNJ2 gene which encodes the inward-rectifying potassium channel, Kir2.1, found in skeletal muscle, cardiac muscle and also plays a role in bone development(14). ATS is characterised by a triad of periodic paralysis, cardiac arrhythmias and distinctive features (short stature, mandibular hypoplasia, low set ears, clinodactyly, and syndactyly). However, there is considerable clinical heterogeneity in clinical presentation(15). The condition is dominantly inherited with predominantly missense mutations(16).

A significant proportion of patients with periodic paralysis from any cause develop a fixed proximal weakness and this requires further evaluation in longitudinal cohorts(17).

\subsection{Symptomatic Treatment}

While there is currently no cure, symptomatic management in these groups can be very effective. Sodium channel blockers have been used to reduce myotonia. Mexiletine has been shown to be effective in a large randomised-controlled multi-centre trial(18). Potassium supplementation, or potassium sparing agents such as spironolactone may be effective in hypokalaemic periodic paralysis(19) and potassium wasting diuretics e.g. thiazides in hyperkalaemic periodic paralysis. Acetazolamide and other carbonic anhydrase inhibitors can be effective in reducing symptoms of muscle weakness in all forms of periodic paralysis. (20). Cardiac screening is essential in AndersenTawil Syndrome because of the risk of cardiac arrhythmia(14). Education about the condition, trigger avoidance and lifestyle management is pivotal.

\section{Improving methodology: Sanger Sequencing to Next Generation Sequencing}

First generation genetic sequencing methods developed by Frederick Sanger in 1975 utilise RNA primers and labelled substrates to detect genetic mutations in families(21). Although very accurate, it is a costly and time-consuming method. Next generation sequencing (NGS), allowing parallel sequencing of DNA strands via a gene panel, has markedly improved diagnostic rates and times while simultaneously reducing cost(21). This evolution of testing at the National Hospital for 
Neurology and Neurosurgery (NHNN) has improved diagnostic rates (Figure 2) which has led to more accurate prevalence estimates. Myotonia congenita, the most common of the muscle channelopathies, in 2019 has an estimated prevalence of 1.17 per 100000 , which is double the estimated prevalence prior to the implementation of next generation sequencing in 2013.

The original four gene next generation sequencing panel for classical skeletal muscle channelopathies has been expanded to seven genes. ATP1A2 was included after discovery as a new gene implicated in Hypokalaemic Periodic Paralysis with additional central nervous system features including epilepsy(22). Rather than an ion channel, ATP1A2 encodes a Na/K-pump that regulates skeletal muscle excitability.

Mutations in genes that are not ion channels or that are not expressed in skeletal muscle can present with symptoms associated with skeletal muscle channelopathies.SLC2A1 is implicated in Glucose Transporter Deficiency Syndrome(23). While this is not a skeletal muscle channelopathy, the episodic symptoms predominantly affect the lower limbs and are often triggered by movement or exercise, which can cause diagnostic confusion with periodic paralysis. Glucose Transport Deficiency syndromes are highly treatable and should not be missed. CACNA1A encodes calcium channel $C_{v} 2.1$ with neuronal expression. It is implicated in Familial Hemiplegic Migraine and Episodic Ataxia type 2(24). These conditions can also have overlapping symptoms or cause diagnostic confusion with presentations of skeletal muscle channelopathies including paresis, and share common triggers. Expansion from a four gene to a seven-gene panel has improved diagnostic rates of previously undiagnosed rare causes of channelopathies and allows parallel diagnosis of channelopathy mimics.

Pedigrees who are negative for the Muscle Channelopathy gene panel, often undergo further sequencing. Whole exome sequencing can be used as a research tool instead of gene panel sequencing to identify novel mutations in pedigrees. Wei et al. describe the recent identification of two novel compound heterozygous mutations in CLCN1 using whole exome sequencing. They then combined this with Sanger sequencing of parents and siblings for the identified mutations to explore segregation(25). The increased detection rate of variants of uncertain significant (VUS) with whole exome sequencing, necessitates additional processes such as segregation analysis and functional studies to confirm or exclude pathogenicity. One particular advantage of whole exome sequencing over gene panels, is the ability to re-interrogate the genetic data if, for example, new genetic mutations or genes are identified for the specified phenotype.

However, widespread and more economical access to whole genome sequencing is overtaking the use of exome sequencing. Whole genome sequencing is particularly advantageous in providing a higher read depth (30x versus 20x) as well as detecting deep intronic variants, non-coding regulatory RNAs and copy number variants which may account for mutations in pedigrees with no mutations identified on the Channelopathy gene panel or whole exome sequencing(21). Tools such as GeneMatcher additionally allow international collaboration in order to identify similar ultra-rare phenotypes, which assists in filtering variants(26).

The gene panel approach remains the gold standard in clinical genetic diagnosis, now supplemented by whole genome sequencing for undiagnosed genetic cases. 


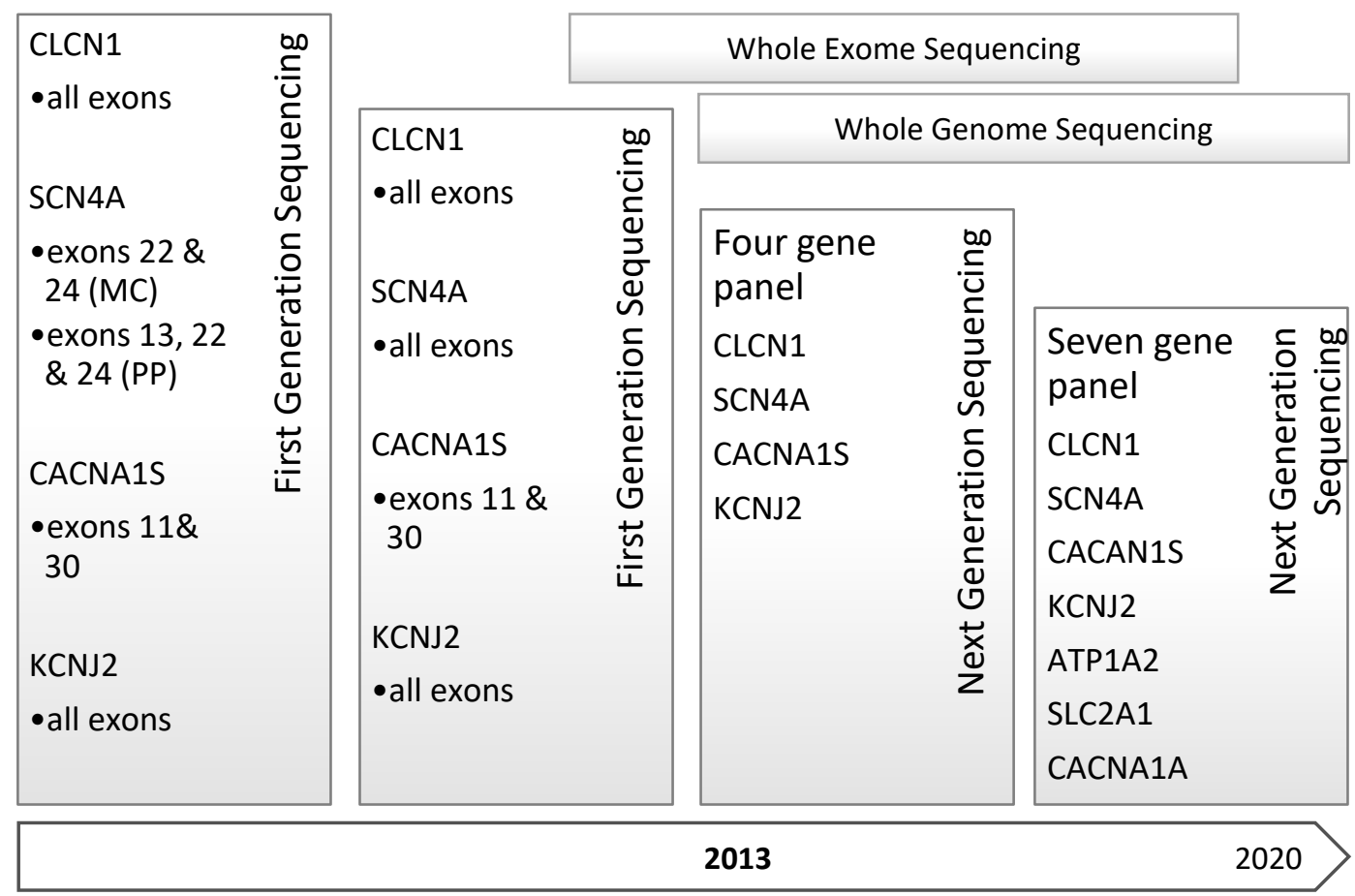

Figure 2: Evolution of Genetic Sequencing over time in Skeletal Muscle Channelopathies at NHNN

\section{Improving genetic diagnostics in Chloride channelopathies}

Mutations in CLCN1 reduce chloride conductance ultimately leading to muscle membrane hyperexcitability manifesting as myotonia(27). Mutations in the gene occur across all exons. A cluster of mutations in exon eight with dominant pedigrees has been reported(5).

The electrophysiological impacts of these mutations, grouped by inheritance, have been studied using electrophysiological techniques in cell based expression systems. Studies typically demonstrate that dominant myotonia congenita occurs as a result of mutated subunits causing a dominantnegative effect on the wild-type subunit(4). Recessive mutations cause a loss of function of the mutated subunit only(28).

However, more recently, it has become clear that some mutations in the same locus can cause either dominant or recessive inheritance patterns, as illustrated in figure 3. Dominant inheritance with reduced penetrance, appearing as recessive pedigrees, has been a proposed mechanism(29). Given that the most common dominant variant Gly230Gly is also found in pedigrees with reported recessive inheritance, it is feasible that no dominant variant has full penetrance and that an accurate phenotype-genotype correlation might be difficult to establish. 


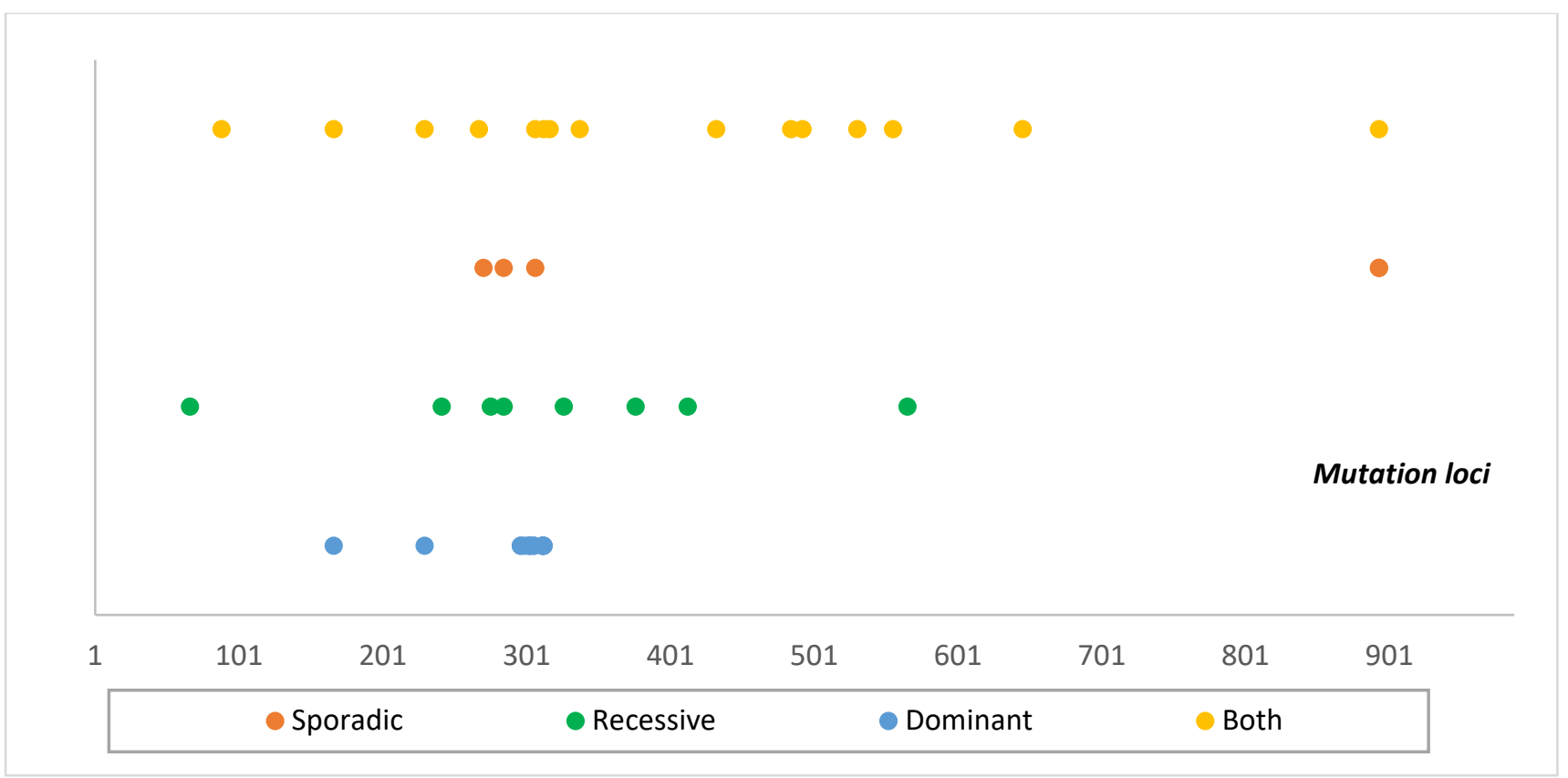

Figure 3: A representation of locations of a set of MC mutations in CLCN1 across the loci of the gene, grouped by mode of inheritance. Both $=$ found in pedigrees with either dominant or recessive reported inheritance patterns.

In patients with a pedigree suggestive of recessive myotonia congenita with a point mutation or exonic deletion/duplication on one allele only, or in those with a typical phenotype and no identified mutations on NGS, intragenic deletions and duplications should be considered. This requires multiplex ligation-dependent probe amplification (MPLA) analysis. Raja Rayan et al. identified exon deletions or duplications in $6 \%$ patients with recessive myotonia congenita using MLPA(30).

\section{Improving genetic diagnostics in Sodium Channelopathies}

\subsection{Correlation between functional studies and phenotypes of myotonia and periodic paralysis}

Mutations in SCN4A found in patients with myotonia or periodic paralysis result in abnormal gain of function of $\mathrm{Na}_{v} 1.4(7)$. The sodium channel is responsible for the depolarising current of a muscle action potential(28). Enhanced currents through $\mathrm{Na}_{v} 1.4$, can increase muscle excitability and lead to myotonia as seen in Paramyotonia congenita or Sodium channel myotonia. Excess sodium influx can lead to depolarisation of the muscle, sodium channel inactivation and inability of the muscle to be activated again causing paralysis as seen in Hyperkalaemic Periodic Paralysis(31). Gain-of-function as a common pathogenic mechanism explains the overlapping symptoms of both myotonia and paralysis in some patients.

A minority of cases of Hypokalaemic Periodic Paralysis are also caused by $\mathrm{Na}_{v} 1.4$ mutations. The sodium channel is formed of four similar trans-membrane domains that are each made up of six segments as shown in Figure 4(7). The first four helices (S1-S4) form a voltage sensing domain, while the last two helices (S5-S6) from all four repeats form the central pore through which ions pass. The sodium channel mutations causing hypokalaemic periodic paralysis, cluster in the fourth transmembrane segment (S4) of each domain. The HypoPP associated mutations neutralise a charged arginine residue in the $\mathrm{S} 4$ segment and allow an inward leak current (known as a gating pore current) through the voltage sensing domain of $\mathrm{Na}_{v} 1.4$. This leak current is considered the key 
component underlying the depolarisation and paralysis of the muscle of patients with hypokalaemic periodic paralysis(32).

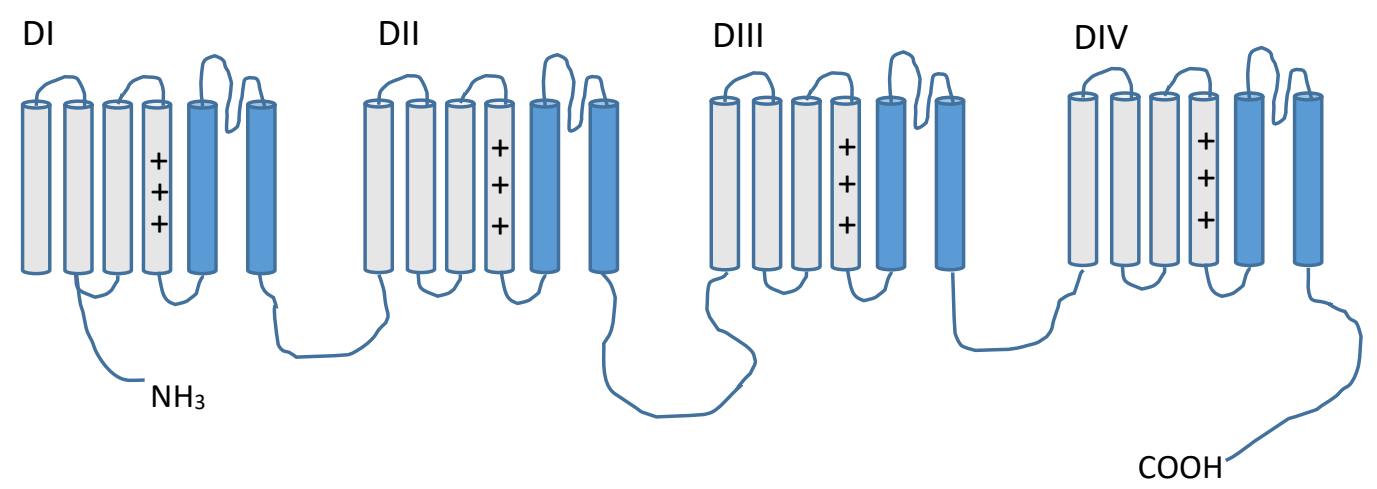

Figure 4: Topographic representation of Sodium Channel ( $\left.\mathrm{Na}_{\mathrm{v}} 1.4\right)$. Four domains (repeats) are each made up of six transmembrane segments. Segments 1-4(grey) form the voltage-sensing domains, segments S5-S6 form the pore. The plus signs illustrate the positively charged residues in the S4 segment where most mutations in hypokalaemic periodic paralysis are seen.

There are some reports of Nav1.4 mutations causing HypoPP but with mechanisms other than gating pore currents(33). A patient carried homozygous SCN4A variants with the mutant channel presenting both loss- and gain-of-function features in functional analysis. It is likely that the homozygous loss-of-function features reduce the sodium currents and consequently a small depolarisation induced inactivation which may result in reduction of sodium current availability to a level below that required to sustain muscle force. Clinical features of periodic paralysis have also been described in patients with homozygous SCN4A mutation but also with features of myasthenic syndrome, see below(34).

\subsection{Novel SCN4A Channelopathies: Congenital Myasthenic Syndrome}

Homozygous or compound heterozygous loss-of-function Nav1.4 variants have been described in cases of congenital myasthenic syndromes (CMS). Patients with classical congenital myasthenic syndromes present with fluctuating weakness and muscle fatigue(35). Fixed muscle weakness may also occur with additional neonatal features such as hypotonia(36). A subset of patients with similar presentations but negative for mutations associated with congenital myasthenia were found to have SCN4A sodium channel mutations(34). The patients may also present with periodic paralysis or myopathic features(34,37-39). Most patients do not appear to experience stiffness or myotonia and myotonia appears to be rarely seen on EMG.

All thus far reported SCN4A related myasthenia mutations demonstrate enhance fast inactivation of Nav1.4 channel4(38). A use-dependent current attenuation occurs as a result of longer recovery from the fast inactivation. This use-dependent effect explains the fatigability and fluctuation. Additionally, varying Nav1.4 availability depending on the depolarisation state of the muscle, may explain the episodic nature of the myasthenic presentations (38).

The EMG and neurophysiology changes seen in CMS associated with a SCN4A mutation, may help in differentiating these patients from classical CMS(39). Neurophysiological investigations have 
reported $50 \%$ decrement in the compound muscle action potential (CMAP) upon conditioning impulses of $10 \mathrm{~Hz}$ for one minute(39). This may relate to use dependent accumulation of sodium channels in the inactivated state. No decrement was seen at the standard $2 \mathrm{~Hz}$ stimulation.

With few differentiating features, the diagnosis of this subset of patients is challenging but important due to treatment implications. Patients with SCN4A mutations may be more amenable to treatment traditionally used in channelopathies over those used in myasthenia. Tsujino et al used acetazolamide at a dose of $250 \mathrm{mg}$ twice daily and described consequent prevention of respiratory and bulbar weakness(39). The mechanism of carbonic anhydrase inhibitors (acetazolamide) for treatment of PP or SCN4A associated CMS is unknown. Clinical trials are required to establish efficacy of acetazolamide in CMS associated with SCN4A mutations.

\subsection{Novel SCN4A Channelopathies: Congenital Myopathy}

Loss of function SCN4A mutations can cause congenital myopathy or foetal hypokinesia. These recessive cases were originally reported by Zaharieva et al. in 2015, and although currently rare, it is likely that with increased sequencing throughput and the known association of SCN4A biallelic variants with congenital myopathy, the number of cases will rise. To date, 13 patients from nine pedigrees are reported. Seven patients died peri-partum, and additional cases required respiratory support early in life (40).

The patterns of congenital myopathy caused by SCN4A mutations appear to be axial and proximal predominant with eight of 13 patients having facial weakness. All newborns were hypotonic. This pattern is seen commonly in all causes of congenital myopathies(41). Notably, episodic symptoms often considered to be classical of channelopathies were only seen in two patients and are not a sensitive clinical feature in this cohort to prompt activation of genetic testing for the channelopathy gene panel. Fetal hypokinesia was present in ten patients and may provide pre-partum diagnostic clues or may prompt investigation for features of sodium channelopathies in the parents.

Similar to CMS associated SCN4A mutations, the congenital myopathy associated mutations cause loss of function. However, unlike CMS associated variants, at least one the alleles for the congenital myopathy cohort appears to be null. The mutation in the second allele causes partial loss of function. The more permanent and larger amplitude loss of available sodium channels may explain the fixed weakness in SCN4A myopathy patients. In almost all cases, at least one of the variants shows full loss of function consistent with severe congenital myopathy. The Arg1142Gln mutation causes mild loss of function and was found to be in homozygous in one pedigree with variable presentation (Sloth et al.). A severe presentation of SCN4A with two SCN4A null alleles is thought to have led to the in utero or at birth fatalities(40).

Unlike classical SCN4A channelopathies, both SCN4A-associated myasthenia and myopathy are recessively inherited. The parents and adult family members who are heterozygous carriers are typically unaffected.

Recognising SCN4A mutations as a potential cause of congenital indicates that SCN4A should be included in future panels for genetically undiagnosed cases of congenital myasthenias and myopathies. Additionally, accumulating clinical and genetic data may lead to insights into potential channel targeted symptomatic treatment(42). 


\begin{tabular}{|c|c|c|c|c|c|c|}
\hline SCN4A & In utero & Neonatal & $\begin{array}{l}\text { Distribution } \\
\text { of myopathy }\end{array}$ & $\begin{array}{l}\text { Respiratory } \\
\text { Support }\end{array}$ & $\begin{array}{l}\text { Superimposed } \\
\text { episodic } \\
\text { weakness }\end{array}$ & (ref) \\
\hline $\begin{array}{l}\text { Arg104His + } \\
\text { Arg1135Cys }\end{array}$ & $\begin{array}{l}\text { Fetal } \\
\text { hypokinesia }\end{array}$ & $\begin{array}{l}\text { Hypotonia, } \\
\text { weak cry \& } \\
\text { suck. }\end{array}$ & $\begin{array}{l}\text { Proximal and } \\
\text { axial }\end{array}$ & $\begin{array}{l}\text { BiPAP from } \\
\text { age } 12\end{array}$ & Yes & $(42)$ \\
\hline $\begin{array}{l}\text { Arg1142GIn + } \\
\text { Cys375Arg } \\
\text { (2 patients) }\end{array}$ & Not reported & Hypotonia & $\begin{array}{l}\text { Face, } \\
\text { proximal. }\end{array}$ & No & No & (43) \\
\hline $\begin{array}{l}\text { Ser1120Leu + } \\
\text { c.1306+1 G>A } \\
\text { (3 patients) }\end{array}$ & $\begin{array}{l}\text { Polyhydramnios } \\
\text {, premature. }\end{array}$ & $\begin{array}{l}\text { Hypotonia, } \\
\text { Dysphagia }\end{array}$ & $\begin{array}{l}\text { Proximal, } \\
\text { axial, facial. }\end{array}$ & No & No & (44) \\
\hline $\begin{array}{l}\text { Homozygous } \\
\text { Arg1142GIn } \\
\text { ( } 2 \text { patients) } \\
\end{array}$ & Normal & Dysphagia & Diffuse & No & No & (45) \\
\hline $\begin{array}{l}\text { Arg104His + } \\
\text { Arg1135Cys }\end{array}$ & $\begin{array}{l}\text { Fetal } \\
\text { hypokinesia }\end{array}$ & $\begin{array}{l}\text { Hypotonia, } \\
\text { weak cry }\end{array}$ & $\begin{array}{l}\text { Facial, } \\
\text { proximal and } \\
\text { axial }\end{array}$ & Yes & Yes & (46) \\
\hline $\begin{array}{l}\text { Arg225Trp + } \\
\text { Cys1209Ph }\end{array}$ & Normal & Hypotonia & $\begin{array}{l}\text { Facial, axial } \\
\text { an proximal }\end{array}$ & Yes & No & (46) \\
\hline $\begin{array}{l}\text { Gin470X } \\
+ \text { His1782GInfs } \\
65\end{array}$ & Polyhydraminos & Hypotonia & Facial, axial & Yes & No & (46) \\
\hline $\begin{array}{l}\text { Asp1069Asn + } \\
\text { Ala1049VfsX5 } \\
0\end{array}$ & $\begin{array}{l}\text { Fetal } \\
\text { hypokinesia, } \\
\text { polyhydramnios }\end{array}$ & $\begin{array}{l}\text { Hypotonia, } \\
\text { w eak cry }\end{array}$ & Facial, axial & Yes & No & $(46)$ \\
\hline $\begin{array}{l}\text { Asp1069N + } \\
\text { Asn1049VfsX5 } \\
0\end{array}$ & $\begin{array}{l}\text { Fetal } \\
\text { hypokinesia } \\
\text { Polyhydramnios } \\
\text { Finger flexion } \\
\text { contractions } \\
\end{array}$ & $\begin{array}{l}\text { Died } \\
\text { 5hours } \\
\text { post } \\
\text { delivery }\end{array}$ & & & & (46) \\
\hline $\begin{array}{l}\text { Homozygous } \\
\text { Pro382Thr }\end{array}$ & $\begin{array}{l}\text { Hypokinesia } \\
\text { Polyhydramnios } \\
\text { Contractures }\end{array}$ & $\begin{array}{l}\text { Died } \\
\text { minutes } \\
\text { post } \\
\text { delivery }\end{array}$ & & & & (46) \\
\hline $\begin{array}{l}\text { Homozygous } \\
\text { Pro382Thr }\end{array}$ & $\begin{array}{l}\text { Talipes, } \\
\text { contractures } \\
\text { Hypokinesia } \\
\text { Hydrops, } \\
\text { polyhydramnios }\end{array}$ & $\begin{array}{l}\text { In utero } \\
\text { death ( } 31 \\
\text { weeks) }\end{array}$ & & & & $(46)$ \\
\hline $\begin{array}{l}\text { Homozygous } \\
\text { Pro382Thr }\end{array}$ & $\begin{array}{l}\text { Hypokinesia, } \\
\text { polyhydramnios } \\
\text { Talipes, hydrops }\end{array}$ & $\begin{array}{l}\text { Death } \\
\text { during } \\
\text { delivery (36 } \\
\text { weeks) } \\
\end{array}$ & & & & $(46)$ \\
\hline
\end{tabular}




\begin{tabular}{|c|c|c|c|}
\hline $\begin{array}{l}\text { Met203Lys + } \\
\text { Tyr1593X }\end{array}$ & $\begin{array}{l}\text { Polyhydramnios } \\
\text { Talipes, hydrops }\end{array}$ & $\begin{array}{l}\text { In utero } \\
\text { death ( } 29 \\
\text { weeks) }\end{array}$ & (46) \\
\hline $\begin{array}{l}\text { Met203Lys + } \\
\text { Tyr1593X }\end{array}$ & $\begin{array}{l}\text { Hypokinesia, } \\
\text { contractures, } \\
\text { talipes, } \\
\text { polyhydramnios } \\
\text {, hydrops }\end{array}$ & $\begin{array}{l}\text { Death } 8 \\
\text { hours post } \\
\text { delivery }\end{array}$ & (46) \\
\hline $\begin{array}{l}\text { Met203Lys + } \\
\text { Tyr1593X }\end{array}$ & $\begin{array}{l}\text { Hypokinesia, } \\
\text { contractures, } \\
\text { polyhydramnios } \\
\text {, hydrops }\end{array}$ & $\begin{array}{l}\text { Pregnancy } \\
\text { terminated } \\
28 \text { weeks }\end{array}$ & (46) \\
\hline
\end{tabular}

Table 1: Cases in the literature of SCN4A mutations causing a congenital myopathy phenotype. Ref= reference

\subsection{Novel presentations of SCN4A channelopathies: Laryngospasm}

Laryngospasm can be a life-threatening phenomenon in neonates causing severe hypoxia(47). Myotonia has been reported to lead to constriction of the laryngeal muscles and laryngospasm. SCN4A mutations have been reported in the literature in neonates presenting with respiratory distress and stridor(47-49). These mutations typically result in a defect in the inactivation in of the sodium channel. Recurrent apnoea was reported in the neonates and myotonia was seen on electromyography (EMG).

Why oropharyngeal myotonia can occur in isolation and early in life remains unclear. Recognition of this genotype-phenotype association is important as the life-threatening laryngospasm and recurrent apnoea may be responsive to treatment with sodium channel blockers such as mexiletine(47). Prospective review of neonates and deep clinical phenotyping including features of the pregnancy and maternal factors will be important to determine predictive factors for the development of laryngospasm. Ultimately, early molecular diagnostics will be important in this cohort.

\subsection{Novel presentations of SCN4A channelopathies: SCN4A mutations as a factor in Sudden Infant Death Syndrome (SIDS)}

Sudden infant death is a devastating syndrome and the leading cause of post-neonatal death in developed countries. The cause of death in Sudden Infant Death Syndrome is unknown; however, several endo- and exogenic factors including prone sleeping position and male sex have been identified as contributing elements(50). SCN4A mutations that resulted in changes in Nav1.4 channel function similarly to those reported in cases of classical and novel Nav1.4 channelopathies were found in a subset of a SIDS cohort. Higher frequency of these variants in SIDS than in the control cohort suggests that they could contribute to terminal respiratory failure in combination with other risk factors. Rare (less than 1/20000 allele frequency) SCN4A mutations with changes in channel function typical for SCN4A channelopathies were identified in four of 278 infants (1.4\%) of this European cohort. The role and mechanism of SCN4A as a factor in SIDS requires further evaluation in larger and more heterogeneous cohorts. 


\section{Improved understanding of co-existing mutations.}

\subsection{Co-existing SCN4A and CLCN1 mutations.}

The presence of concomitant mutations of SCN4A and CLCN1 may act as phenotypic modifiers and supports the use of a clinical gene panel, allowing simultaneous sequencing of all genes associated with skeletal muscle channelopathies.

Combining the cases reported in the literature with our cases, there are a total of 14 patients with concomitant sodium and chloride channel mutations, Table 2 . Functional data is reported in three of these.

Maggi et al. describe a 26 year old with myotonia and episodes of transient weakness with two mutations (SCN4A + CLCN1) identified (51). Functional studies of the Sodium channel mutation in HEK293 cells illustrated impairment of fast inactivation, which would be consistent with myotonia. Impairment of slow inactivation was also demonstrated which is often associated with more prolonged attacks of weakness which did not occur in this patient. It is possible that the CLCN1 mutation was a modifier in this situation and protected against more prolonged attacks of paralysis(51).

In our cohort, Thor et al. postulate a similar protective role of the CLCN1 mutation against more prolonged attacks of paralysis. A patient with a Nav1.4 S4 arginine mutation, Arg222Gln, presented with predominant myotonia(52). Other mutations in the same location present with HypoPP (Arg222Trp and Arg222Gly). The Arg222Gln variant conducted small gating pore currents but also caused gain of function of the main pore features. The patient carried a concomitant heterozygous CLCN1 variant associated with recessive MC pedigrees. It was proposed that this heterozygous variant may worsen the myotonic presentation caused by the main pore gain-of-function and potentially protect against more fulminant attacks of paralysis in this patient(52). In this case, muscle velocity recovery cycle (MVRC) analysis was utilised to demonstrate that the CLCN1 variant increases the excitability parameters of the patient compared to patients with a SCN4A variant only $(52,53)$. MVRC may be a useful tool in addition to functional expression to explore pathogenicity in cases of dual mutations.

Kato et al. describe a 27 year old gentleman with episodic weakness as well as myotonia who harboured two heterozygous mutations - a SCN4A mutation and CLCN1 mutation(54). The CLCN1 mutation was also detected in the proband's mother who had myotonia but no weakness. His father was negative for both mutations. It is possible that both mutations contribute to the phenotype in the proband resulting in myotonia (autosomal dominantly inherited from his mother) and a spontaneous SCN4A mutation likely to explain the episodic paralysis. The sodium channel mutation was expressed in HEK293 cells and demonstrated significantly enhanced activation consistent with the clinical episodes of paralysis (54). Exploration of the CLCN1 variant with functional expression is required. MVRC analysis may additionally be useful in this setting.

These 14 cases have been identified since the routine use of next generation sequencing, and have provided significant insights. The phenotypic variability and functional data provide cumulative evidence for the role of second variants acting as genetic modifiers. Ongoing accumulation of additional cases with deep phenotyping and functional expression will allow us to better understand the genotype-phenotype correlations. Where reported, the concomitant SCN $4 A / C L C N 1$ cases typically respond well to mexiletine. 


\begin{tabular}{|l|l|l|l|}
\hline SCN4A mutation & CLCN1 mutation & Patients & Reference \\
\hline Thr1313Met & Pro480fs & 1 & NHNN cohort \\
\hline Val1589Met & Arg894* & 1 & NHNN cohort \\
\hline Val1598Met & Phe167Leu & 1 & NHNN cohort \\
\hline Val1598Met & Pro480fs & 2 & NHNN cohort \\
\hline Gly1306Val & Ala313Val & 3 & NHNN cohort \\
\hline Arg222Trp & Thr550= & 1 & $\begin{array}{l}\text { NHNN cohort } \\
\text { Thor et al. 2019 (52) }\end{array}$ \\
\hline Phe1290Leu & Glu950Lys & 1 & Kato et al. 2016 (55) \\
\hline Gly1306 & Met485Val & 1 & Furby et al. 2014 (56) \\
\hline Arg1337Pro & Thr268Met & 1 & Furby et al. 2014 (56) \\
\hline Ile693Met & Arg976X & 1 & Furby et al. 2014 (56) \\
\hline Asn1297Ser & Gly167Ley & 1 & $\begin{array}{l}\text { Maggi et al. 2017 } \\
\text { (51) }\end{array}$ \\
\hline
\end{tabular}

Table2: Our cases (NHNN = National Hospital for Neurology and Neurosurgery) and cases reported in the literature of concomitant SCN4A and CLCN1 mutations.

\subsection{Co-existing CLCN1/SCN4A and Myotonic Dystrophy}

Mutations in genes causing skeletal muscle channelopathies can co-exist with myotonic dystrophy (DM) and can modify the clinical phenotype. Myotonic dystrophy is important to diagnose due to the additional cardiac phenotype and need for cardiac screening(57). Inappropriate regulation of CLC-1 splicing and consequent reduction in skeletal muscle chloride channel has been a proposed mechanism of myotonia in myotonic dystrophy type 1 and 2(58). Consequently, mutations in skeletal muscle ion channels associated with myotonia may exacerbate the presentation of myotonic dystrophy. There are several cases in the literature described with concomitant mutations, Table 3.

Bugiardini et al. described modification of the Myotonic Dystrophy type 2 (DM2) phenotype with a concomitant SCN4A mutation(59). The patient had early and severe myotonia, which is atypical for myotonic dystrophy type two. Binda et al. also report a patient with DM2 as well as a sodium channel mutation(60). While the sodium channel mutation (S906T) is a polymorphism affecting approximately $5 \%$ of people in healthy control databases, they propose that this mutation in SCN4A is modifying of the gene for DM2. Additionally, the proband's mother who also had DM2 but did not carry the SCN4A mutation, had a different phenotype with more mild myotonia, also in support of the modifying effect of the mutated SCN $4 A$ in the proband.

In our cohort, a 62 year old female presenting with myotonia was diagnosed with a likely sodium channel myotonia with a novel SCN4A mutation (Asn160Ser), however mismatching segregation studies as well as development of weakness prompted testing for myotonic dystrophy type one and type two. A CNBP (seen in DM2) expansion was subsequently identified which was likely to be pathogenic in this case and segregated in the family. Subsequent functional studies did not find any current changes caused by the SCN4A Asn160Ser mutation. This case illustrates that not all sodium channel mutations appear to modify the phenotype of myotonic dystrophy. Careful phenotyping to guide appropriate genetic testing alongside segregation analysis and interrogation with functional expression studies is key.

Interestingly, all reported cases with concomitant mutations occur with myotonic dystrophy 2 . This may be because CNBP is more susceptible to modification by SCN4A or CLCN1. It is also possible that systemic features (e.g. frontal balding, cataracts, diabetes, hormonal imbalance) are more 
prominent phenotypic features in DM1 and that more subtle modifications of phenotype related to myotonia may go unrecognised. Co-expression in cell or animal-based models are required to further understand the impact and interactions of these concomitant mutations.

\begin{tabular}{|c|l|l|l|l|l|}
\hline SCN4A & CLCN1 & DM & $\begin{array}{l}\text { Modification } \\
\text { of Phenotype }\end{array}$ & Electrophysiology & Reference \\
\hline Ser906Thr & - & $\begin{array}{l}\text { CNBP } \\
\text { expansion }\end{array}$ & $\begin{array}{l}\text { Severe and } \\
\text { early onset } \\
\text { myotonia }\end{array}$ & $\begin{array}{l}\text { Hyperpolarization } \\
\text { shift/enhanced } \\
\text { sodium current. }\end{array}$ & $\begin{array}{l}\text { Binda et al. } \\
\text { 2018 (60) }\end{array}$ \\
\hline Pro72Leu & - & $\begin{array}{l}\text { CNPB } \\
\text { expansion } \\
\text { (2650 CCTG } \\
\text { repeat) }\end{array}$ & $\begin{array}{l}\text { Severe and } \\
\text { early onset } \\
\text { myotonia }\end{array}$ & $\begin{array}{l}\text { Hyperpolarizing } \\
\text { shift. }\end{array}$ & $\begin{array}{l}\text { Bugiardini et } \\
\text { al. 2015 (61) }\end{array}$ \\
\hline- & Phe413Cys & $\begin{array}{l}\text { CNBP } \\
\text { expansion }\end{array}$ & $\begin{array}{l}\text { Severe } \\
\text { myotonia }\end{array}$ & $\begin{array}{l}\text { Mild loss of } \\
\text { function. }\end{array}$ & $\begin{array}{l}\text { Sun et al. } \\
\text { 2011. (62) }\end{array}$ \\
\hline- & Phe167Leu & $\begin{array}{l}\text { CNBP } \\
\text { expansion }\end{array}$ & $\begin{array}{l}\text { Severe } \\
\text { myotonia }\end{array}$ & $\begin{array}{l}\text { Mild loss of } \\
\text { function. }\end{array}$ & $\begin{array}{l}\text { Cardani et } \\
\text { al. 2012 (63) }\end{array}$ \\
\hline
\end{tabular}

Table 3: Cases reported in the literature of concomitant SCN4A or CLCN1 mutations and Myotonic Dystrophy.

\section{New advances in genetic diagnostics of CACNA1S}

CACNA1S codes for the skeletal muscle Cav1.1 calcium channel which is important in excitation contraction coupling(64). Cav1.1 exists in junctional T-tubular membranes in myocytes and forms a signalling complex with RyR-1, figure 5 . A conformational change in the voltage-sensor after depolarisation is transmitted to RyR1 and activates calcium release and contraction(4).

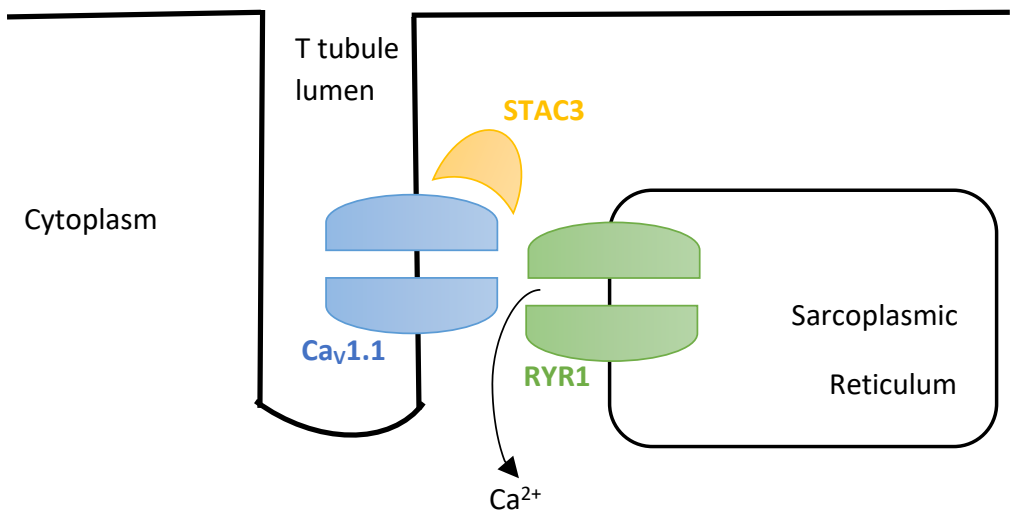

Figure 5: proteins in skeletal muscle crucial in excitation contraction coupling.

In 2013, STAC3, a small adapter protein, was discovered co-localising with Cav1.1 and RyR1 (figure 5) (65). STAC3 knockout mice demonstrated a phenotype seen in mice who have failure of excitation coupling(66). STAC3 is an essential chaperon for Cav1.1 to enable excitation contraction coupling. This discovery also advanced electrophysiological studies of Cav1.1. Prior to this discovery, whole cell patch-clamp systems of Cav1.1 were not effective. When Cav1.1 (including its subunits) and STAC3 
were co-expressed however, the magnitudes of currents and charge movements provided a stable, reproducible technical system to better study Calcium channels(66). This is an important tool to express and interrogate pathogenicity in novel CACNA1S variants.

Most cases of HypoPP are caused by mutations affecting the S4 segments of Cav1.1. The pathomechanism is thought to be identical to SCN4A HypoPP cases. The mutant channels conduct gating pore currents as demonstrated in transfected muscle cells or in a mouse model of CACNA1S HypoPP $(8,67)$. By transient expression in mouse muscles it was shown that the only HypoPP CACNA1S mutation to date not associated with an S4 arginine, Val876Glu also conducts gating pore leak currents(68). Developments in CACNA1S functional expression with STAC3 have recently allowed demonstration of gating pore currents for several Cav1.1 S4 arginine variants(67).

In addition to presentations of classical channelopathies, CACNA1S mutations have been found in other skeletal muscle conditions. Schartner et al. describe 11 patients (seven pedigrees) with severe congenital myopathy, with opthalmoplegia in four patients(40). Whole exome sequencing identified CACNA1S variants. Four families had recessive pedigrees with compound heterozygous mutations identified, and de novo mutations where found in the other three pedigrees. The mutations were further characterised using western blot on muscle biopsies and myotube extracts, as well as $\mathrm{Ca}^{2+}$ release studies demonstrating variable reduction in expression/release. Hunter et al. also described novel CACNA1S variants causing a fixed myopathy(69). The child had neonatal hypotonia, fixed weakness and opthalmoplegia. Whole exome sequencing identified novel CACNA1S variants (Gln1649GInfs*72 + Gln1265His) from unaffected carrier parents. Predictive tools and segregation studies suggested the mutations were pathogenic. While predictive tools and biochemical tools are useful, functional expression of these mutations is likely to be very helpful in exploring pathogenicity and understand mechanism of action. With recent advances in technique with STAC3 co-expression, this is now more available, and may provide significant insight. However, as Cav1.1 physically couples RyR1, pathogenic mechanisms of mutation affecting only the excitation-contraction component of Cav1.1 function cannot be picked up upon heterologous expression.

\section{Advances in Kir Potassium Channelopathies}

KCNJ2 mutations coding for inward rectifying Kir2.1 channels, are identified in Andersen-Tawil Syndrome. While classically, a triad of periodic paralysis, cardiac arrhythmias and distinctive features have been described, several cases in the literature and our recent audit suggests significant phenotypic heterogeneity(70). The phenotype may be predominantly cardiac or weakness, and distinctive features may be subtle. Additionally, new aspects of the syndrome, for example a neurocognitive profile, are coming to light(71). This is likely to be due to improved diagnostic rates.

While compared to other inherited cardiac sodium channelopathies, ATS has a more mild cardiac risk, there is still a risk of cardiac death(72). Further genotype-phenotype studies are required to better understand this risk.

$40 \%$ of patients with an ATS phenotype are genetically undiagnosed(73). In search for additional ATS genes, a pedigree where the proband had periodic paralysis and abnormal electrocardiogram (ECG) demonstrating $U$ waves and a family history of arrhythmias, was investigated(74). The proband did not have any dysmorphic features. Exome capture resequencing analysis identified a variant in KCNJ5 coding for Kir3.4 channels. Functional co-expression of wild type Kir2.1 and mutated Kir3.4 demonstrated a significant reduction in the inward rectifying potassium current(74). Exome analysis 
and functional co-expression were important tools in this new finding and are likely to identify further pathogenic genes in the future.

\section{New Genes implicated in Periodic Paralysis}

Mutations in RYR1, ATP1A2, MT-ATP6 and MT-ATP8 have been recently identified in cases of periodic paralysis. Skeletal muscle ryanodine receptor (RYR1) codes for the main sarcoplasmic reticulum-located calcium release channel in muscle and is critical for excitation contraction coupling. RYR1 mutations are known to cause several muscle phenotypes including congenital myopathies, rhabdomyolysis, myalgia and malignant hyperthermia(75). A periodic paralysis phenotype caused by RYR1 mutations have been reported in four cases to date $(40,76)$. Two patients had childhood onset with congenital myopathy and later episodes of periodic paralysis. The other two did not have myopathy but demonstrated later onset periodic paralysis. Cramps and myalgia were experienced by all patients and typical periodic paralysis triggers such as cold and exercise were described in some.

A heterozygous ATP1A2 mutation was identified in a child with hypokalaemic periodic paralysis but negative for mutations in the known periodic paralysis genes(77). ATP1A2 codes for the alpha2 subunit of Sodium-Potassium-ATPase, which converts ATP energy into electrochemical gradients. It is expressed in both skeletal muscle and brain and the child had additional central nervous system features including epilepsy. Electrophysiological studies demonstrated an aberrant inward leak current akin to that seen in CACNA1S and SCN4A causing hypokalaemic periodic paralysis. This finding further supports the role of the leak current in the pathogenesis of hypokalaemic periodic paralysis.

MT-ATP6 and MT-ATP8 are mitochondrial DNA genes, in which mutations cause classical mitochondrial phenotypes such as Leigh syndrome. Auré et al. report patients in six independent families with periodic paralysis, negative for known genes causing periodic paralysis, in whom they identified pathogenic MT-ATP6/8 mutations(78). Attacks were often triggered by cold, exercise, prolonged sitting or rest after exercise. Development of a motor neuropathy was seen in these patients.

\section{Conclusion}

Advances in genetic understanding and genetic diagnostics of skeletal muscle channelopathies has been a result of improved methodology, deep phenotyping and correlations with genotypes. Understanding concomitant mutation interactions and modification of phenotypes has been a step forward compared to previous single gene studies. Functional characterisation has been valuable in understanding pathomechanisms, exploring pathogenicity of variants as well as interactions between mutations. Accurate genetic diagnosis is essential for correct therapeutic options for skeletal muscle channelopathies with variable and overlapping clinical presentations.

\section{Expert Commentary}

Skeletal muscle channelopathies are rare genetic conditions typically presenting with episodic symptoms across a spectrum from myotonia to periodic paralysis. Advances in genetic diagnostics 
have improved diagnostic rates, significantly improved understanding of genotype-phenotype associations, and broadened the range of phenotypes.

Foremost in improved methodology is next generation sequencing with gene panels, which has enhanced diagnostic rates in our service. This has in turn allowed more accurate disease prevalence estimates.

Next generation sequencing has also allowed the discovery of several new mutations. In addition, there are improved tools such as segregation analysis and predictive programs for interrogating newly identified mutations; functional expression in cell based electrophysiology studies has also been pivotal. Cell based electrophysiology has provided insight into the effect of mutations and the resultant current modifications which has in turn improved our ability to correlate genotypes and phenotypes(32). The ability to functionally express novel variants rapidly and reliably will be invaluable as more variants of uncertain significance are identified.

We describe cases with concomitant mutations acting as potential gene modifiers. In future, functional models co-expressing these dual mutations may provide significant insight into the interaction and potential modification.

Even within single gene skeletal muscle channelopathies, there is significant phenotypic heterogeneity. Within families, the same mutation can cause varying disease severity, can affect regions of the body differently, and can have differing attack triggers. Our current understanding of the reason for this variability is limited. It is possible that gene regulatory elements are important. For example, tissue-specific enhancers may explain the prominence of face and jaw myotonia in subsets of patients or the occurrence of isolated laryngospasm in neonates with sodium channel mutations. Genes responsible for these regulatory roles are not yet identified and the genetic mechanisms may involve non-coding regions, or more complex balanced translocations, inversions or insertions. The ability to identify these variants will be a particular advantage of whole genome sequencing. The ability to then functionally co-express potential modifier genes will be important in determining pathogenicity, mechanistic understanding and genotype-phenotype insights in the future.

Our understanding of phenotypes associated with sodium channel mutations has markedly improved recently, particularly with the appreciation of paediatric phenotypes. Homozygous partial loss of function mutations in SCN4A cause congenital myasthenia or mild to moderate congenital myopathy(79). Compound heterozygous mutations with one partial loss of function mutation and one null mutation appear to cause more severe congenital myopathy. While these associations require further elucidation, the insight into life-threatening phenotypes has been clinically significant.

The association of SCN4A and laryngospasm is clinically important. Treatment of laryngospasm after its occurrence is suboptimal, and identifying neonates with sodium channel mutations may allow treatment with sodium channel blockers to act as a preventative agent for stridor and laryngospasm. In adult populations myotonia in intercostal muscles, the tongue and laryngeal muscles can respond to treatment with sodium channel blockers $(18,80)$. Whether these drugs can be used safely in neonates with stridor requires investigation.

There are several similar potential situations for genotype-phenotype correlation to lead to personalised treatments. For example, congenital myasthenia attributed to a $D O K 7$ may be amenable to 3,4 diaminopyridine while that caused by $S C N 4 A$ may be more amenable to acetazolamide(37). 
Moreover, an understanding of patterns of inheritance has been important. We now appreciate that mutations previously deemed recessive, are also able to cause dominant patterns of inheritance. This is important for genetic counselling. This is particularly significant in some health systems where recessively inherited mutations (expected to have a low likelihood of transmission) have restricted access to preimplantation genetic diagnosis(81). Re-categorisation of mutations as having either dominant or recessive inheritance is crucial in such situations.

From a clinical trial standpoint, stratifying clinically heterogeneous groups by genotypes and functional effect will be useful in the future. For example, patients with a subset of sodium channel mutations that functionally also have gating pores may be more amenable to other treatments besides sodium channel blockers. Appropriate stratification would prevent dilution of study groups with non-responders and would avoid underestimation of treatment effects.

Genetics will continue to be pivotal in improving understanding of broader phenotypes associated with already known muscle channelopathy genes. In addition, modifier and regulatory genes are a poorly understood area that are likely to be involved in the episodic triggered nature of attacks, and phenotypic variability. Understanding this aspect of the muscle channelopathies will be an important advance. Ultimately, advances in genotype-phenotype and genotype-functional characterisation will facilitate better-designed clinical trials and personalised treatment models.

Declaration of Interest: MGH is supported by an MRC strategic ward to establish an International Centre for Genomic Medicine for Neuromuscular Diseases. Our clinical muscle channel service is supported by NHS England Highly Specialised Commissioning. Our work is supported by the UCLH NIHR Biomedical Research Centre. EM is funded by a Wellcome clinical research career development fellowship.

\section{References}

Papers of special note have been highlighted as either of interest $(\bullet)$ or of considerable interest $(\bullet \bullet)$ to readers.

1. Horga A, Rayan DLR, Matthews E, Sud R, Fialho D, Durran SCM, et al. Prevalence study of genetically defined skeletal muscle channelopathies in England. Neurology. 2013;

2. Lossin C, George AL. Chapter 2 Myotonia Congenita. Advances in Genetics. 2008.

3. Statland JM, Fontaine B, Hanna MG, Johnson N, Kissel JT, Sansone VA, et al. A Review of the Diagnosis and Treatment of Periodic Paralysis. Muscle Nerve. 2017;

4. Cannon SC. Channelopathies of skeletal muscle excitability. Compr Physiol. 2015;5(2):761-90.

5. Fialho D, Schorge S, Pucovska U, Davies NP, Labrum R, Haworth A, et al. Chloride channel myotonia: Exon 8 hot-spot for dominant-negative interactions. Brain. 2007;130(12):3265-74.

6. Morales F, Pusch M. An Up-to-Date Overview of the Complexity of Genotype-Phenotype Relationships in Myotonic Channelopathies. Front Neurol. 2020;10(January).

7. Nicole S, Fontaine B. Skeletal muscle sodium channelopathies. Curr Opin Neurol. 2015;28(5):508-14. 
8. Jurkat-Rott K, Rüdel R, Lehmann-Horn F. Muscle Channelopathies: Myotonias and Periodic Paralyses. Neuromuscul Disord Infancy, Childhood, Adolesc A Clin Approach.

2015;(December):719-34.

9. Suetterlin K, Männikkö R, Hanna MG. Muscle channelopathies: Recent advances in genetics, pathophysiology and therapy. Curr Opin Neurol. 2014;27(5):583-90.

10. Fialho D, Griggs RC, Matthews E. Periodic paralysis [Internet]. 1st ed. Vol. 148, Handbook of Clinical Neurology. Elsevier B.V.; 2018. 505-520 p. Available from:

http://dx.doi.org/10.1016/B978-0-444-64076-5.00032-6

11. Drost G, Blok JH, Stegeman DF, Van Dijk JP, Van Engelen BGM, Zwarts MJ. Propagation disturbance of motor unit action potentials during transient paresis in generalized myotonia A high-density surface EMG study. Vol. 124, Brain. 2001.

12. Hokpp S. Hypokalemic Periodic Paralysis Summary Genetic counseling. 2019;1-32.

13. Fontaine B, Khurana TS, Hoffman EP, Bruns GAP, Haines JL, Trofatter JA, et al. Hyperkalemic periodic paralysis and the adult muscle sodium channel $\alpha$-subunit gene. Science (80- ). 1990;250(4983):1000-2.

14. Krych M, Biernacka EK, Ponińska J, Kukla P, Filipecki A, Gajda R, et al. Andersen-Tawil syndrome: Clinical presentation and predictors of symptomatic arrhythmias - Possible role of polymorphisms K897T in KCNH2 and H558R in SCN5A gene. J Cardiol. 2017;70(5):504-10.

15. Kimura H, Zhou J, Kawamura M, Itoh H, Mizusawa Y, Ding WG, et al. Phenotype variability in patients carrying KCNJ2 mutations. Circ Cardiovasc Genet. 2012;5(3):344-53.

16. Tristani-Firouzi M, Etheridge SP. Kir 2.1 channelopathies: The Andersen-Tawil syndrome. Pflugers Arch Eur J Physiol. 2010;460(2):289-94.

17. Meola G, Hanna MG, Fontaine B. Diagnosis and new treatment in muscle channelopathies. J Neurol Neurosurg Psychiatry. 2009;80(4):360-5.

18. Bundy BN, Wang Y, Sansone VA, Venance SL, Ciafaloni E, Matthews E, et al. Mexiletine for Symptoms and Signs of Myotonia in Nondystrophic Myotonia. J Am Med Assoc. 2012;308(October 3):1357-65.

19. Statland JM, Fontaine B, Hanna MG, Johnson NE, Kissel JT, Sansone VA, et al. Review of the Diagnosis and Treatment of Periodic Paralysis. Muscle and Nerve. 2018;57(4):522-30.

20. Sansone V, Tawil R. Management and Treatment of Andersen-Tawil Syndrome (ATS).

21. Koboldt DC, Steinberg KM, Larson DE, Wilson RK, Mardis ER. XThe next-generation sequencing revolution and its impact on genomics. Cell [Internet]. 2013;155(1):27. Available from: http://dx.doi.org/10.1016/j.cell.2013.09.006

22. Castañeda MS, Zanoteli E, Scalco RS, Scaramuzzi V, Caldas VM, Reed UC, et al. A novel ATP1A2 mutation in a patient with hypokalaemic periodic paralysis and CNS symptoms. Brain. 2018;141(12):3308-18.

23. Hao J, Kelly DI, Su J, Pascual JM. Clinical aspects of glucose transporter type 1 deficiency: Information from a global registry. JAMA Neurol. 2017;74(6):727-32.

24. Denier C, Ducros, Anne, Durr A, Eymard B, Chassande B, Tournier-Lasserve E. Mutation causing episodic ataxia type 2. Arch Neurol. 2001;58:292-5.

25. Wei Z, Huaxing M, Xiaomei W, Juan W, Xueli C, Jing Z, et al. Identification of two novel 
compound heterozygous CLCN1 mutations associated with autosomal recessive myotonia congenita. Neurol Res [Internet]. 2019;41(12):1069-74. Available from:

https://doi.org/10.1080/01616412.2019.1672392

26. Sobreira N, Schiettecatte F, Valle D, Hamosh A. GeneMatcher: A Matching Tool for Connecting Investigators with an Interest in the Same Gene. Hum Mutat. 2015;36(10):92830.

27. Imbrici P, Altamura C, Pessia M, Mantegazza R, Desaphy J-F, Camerino DC. ClC-1 chloride channels: state-of-the-art research and future challenges. Front Cell Neurosci. 2015;

28. Cannon SC. Pathomechanisms in Channelopathies of Skeletal Muscle and Brain. Annu Rev Neurosci. 2006;29(1):387-415.

29. Koch MC, Steinmeyer K, Lorenz C, Ricker K, Wolf F, Otto M, et al. The skeletal muscle chloride channel in dominant and recessive human myotonia. Science (80- ). 1992;257(5071):797800.

30. Raja Rayan DL, Haworth A, Sud R, Matthews E, Fialho D, Burge J, et al. A new explanation for recessive myotonia congenital: Exon deletions and duplications in CLCN1. Neurology. 2012;78(24):1953-8.

31. Huang S, Zhang W, Chang X, Guo J. Overlap of periodic paralysis and paramyotonia congenita caused by SCN4A gene mutations two family reports and literature review. Channels [Internet]. 2019;13(1):110-9. Available from: https://doi.org/10.1080/19336950.2019.1600967

32. Sokolov S, Scheuer T, Catterall WA. Gating pore current in an inherited ion channelopathy. Nature. 2007;446(7131):76-8.

33. Na V, Luo S, Castañeda MS, Matthew E, Sud R, Hanna MG, et al. Hypokalaemic periodic paralysis and myotonia in a patient with homozygous mutation p . R1451L in. 2018;(April):112.

34. Habbout $\mathrm{K}$, Poulin $\mathrm{H}$, Rivier $\mathrm{F}$ et al. A recessive Nav1.4 mutation underlies congenital myasthenic syndrome with periodic paralysis. Neurology [Internet]. 2016;86(2):161-9. • Available from:

http://www.embase.com/search/results?subaction=viewrecord\&from=export\&id=L6077894 33\%5Cnhttp://dx.doi.org/10.1212/WNL.0000000000002264

35. Finlayson S, Beeson D, Palace J. Congenital myasthenic syndromes: An update. Pract Neurol. 2013;13(2):80-91.

36. Engel AG. Genetic basis and phenotypic features of congenital myasthenic syndromes [Internet]. 1st ed. Vol. 148, Handbook of Clinical Neurology. Elsevier B.V.; 2018. 565-589 p. Available from: http://dx.doi.org/10.1016/B978-0-444-64076-5.00037-5

37. Elia N, Palmio J, Castañeda MS, Shieh PB, Quinonez M, Suominen T, et al. Myasthenic congenital myopathy from recessive mutations at a single residue in NaV1.4. Neurology. 2019;92(13):E1405-15.

38. Arnold WD, Feldman DH, Ramirez S, He L, Kassar D, Quick A, et al. Defective fast inactivation recovery of Nav1.4 in congenital myasthenic syndrome. Ann Neurol. 2015;77(5):840-50.

39. Tsujino A, Maertenst C, Ohno K, Shen XM, Fukuda T, Harper CM, et al. Myasthenic syndrome caused by mutation of the SCN4A sodium channel. Proc Natl Acad Sci U S A. 2003;100(12):7377-82. 
40. Schartner V, Romero NB, Donkervoort S, Treves S, Munot P, Pierson TM, et al. Dihydropyridine receptor (DHPR, CACNA1S) congenital myopathy. Acta Neuropathol. 2017;133(4):517-33.

41. Nance JR, Dowling JJ, Gibbs EM, Bönnemann CG. Congenital myopathies: An update. Curr Neurol Neurosci Rep. 2012;12(2):165-74.

42. Sarcolemmal I. Acetazolamide can improve symptoms and signs in ion congenital myopathy. 2019;90(2):243-5.

43. Gonorazky HD, Marshall CR, Al-Murshed M, Hazrati LN, Thor MG, Hanna MG, et al. Congenital myopathy with "corona" fibres, selective muscle atrophy, and craniosynostosis associated with novel recessive mutations in SCN4A. Neuromuscul Disord [Internet]. 2017;27(6):574-80. Available from: http://dx.doi.org/10.1016/j.nmd.2017.02.001

44. Mercier S. Clinical / Scientific Notes. 2016;414-7.

45. Sloth CK, Denti F, Schmitt N, Bentzen BH, Fagerberg C, Vissing J, et al. Homozygosity for SCN4A Arg1142GIn causes congenital myopathy with variable disease expression. Neurol Genet. 2018;4(5):e267.

46. Zaharieva IT, Thor MG, Oates EC, Karnebeek C Van, Hendson G, Blom E, et al. Loss-of-function mutations in SCN4A cause severe foetal hypokinesia or ' classical ' congenital myopathy. 2016;(2015):674-91.

47. Lion-François L, Mignot C, Vicart S, Manel V, Sternberg D, Landrieu P, et al. Severe neonatal episodic laryngospasm due to de novo SCN4A mutations: A new treatable disorder. Neurology. 2010;75(7):641-5.

48. Matthews E, Manzur AY, Sud R, Muntoni F, Hanna MG. Stridor as a neonatal presentation of skeletal muscle sodium channelopathy. Arch Neurol. 2011;68(1):127-9.

49. Caietta E, Milh M, Sternberg D, Lépine A, Boulay C, McGonigal A, et al. Diagnosis and outcome of SCN4A-related severe neonatal episodic laryngospasm (SNEL): 2 new cases. Pediatrics. 2013;132(3).

50. Sullivan FM, Barlow SM. Review of risk factors for sudden infant death syndrome. Paediatr Perinat Epidemiol. 2001;15(2):144-200.

51. Maggi L, Ravaglia S, Farinato A, Brugnoni R, Altamura C, Imbrici P, et al. Coexistence of CLCN1 and SCN4A mutations in one family suffering from myotonia. Neurogenetics. 2017;

52. Thor MG, Vivekanandam V, Sampedro-Castañeda M, Tan SV, Suetterlin K, Sud R, et al. Myotonia in a patient with a mutation in an $\mathrm{S} 4$ arginine residue associated with hypokalaemic periodic paralysis and a concomitant synonymous CLCN1 mutation. Sci Rep. 2019;9(1):1-11.

53. Tan SV, Matthews E, Barber M, Burge JA, Rajakulendran S, Fialho D, et al. Refined exercise testing can aid dna-based diagnosis in muscle channelopathies. Ann Neurol. 2011;69(2):32840.

54. Kato H, Kokunai Y, Dalle C, Kubota T, Madokoro Y, Yuasa H, et al. A case of non-dystrophic myotonia with concomitant mutations in the SCN4A and CLCN1 genes. J Neurol Sci. 2016;

55. Kato H, Kokunai Y, Dalle C, Kubota T, Madokoro Y, Yuasa H, et al. A case of non-dystrophic myotonia with concomitant mutations in the SCN4A and CLCN1 genes. J Neurol Sci [Internet]. 2016;369:254-8. Available from: http://dx.doi.org/10.1016/j.jns.2016.08.030

56. Furby A, Vicart S, Camdessanché JP, Fournier E, Chabrier S, Lagrue E, et al. Heterozygous 
CLCN1 mutations can modulate phenotype in sodium channel myotonia. Neuromuscul Disord. 2014;24(11):953-9.

57. Lagrue E, Dogan C, De Antonio M, Audic F, Bach N, Barnerias C, et al. A large multicenter study of pediatric myotonic dystrophy type 1 for evidence-based management. Neurology. 2019;92(8):E852-65.

58. Charlet-B N, Savkur RS, Singh G, Philips A V, Grice EA, Cooper TA. Loss of the Muscle-Specific Chloride Channel in Type 1 Myotonic Dystrophy Due to Misregulated Alternative Splicing several lines of evidence indicate that a gain of function for RNA CUG)n. Mol Cell [Internet]. 2002;10:45-53. Available from: https://ac-els-cdncom.pros.lib.unimi.it:2050/S1097276502005725/1-s2.0-S1097276502005725main.pdf?_tid=d3d35bfe-2f96-4e2c-bc45fa24d930f0ce\&acdnat=1552954806_d7c55953b0dc58758f85dd7979f81813

59. Bugiardini E, Rivolta I, Binda A, Soriano Caminero A, Cirillo F, Cinti A, et al. SCN4A mutation as modifying factor of Myotonic Dystrophy Type 2 phenotype. Neuromuscul Disord [Internet]. 2015;25(4):301-7. Available from: http://dx.doi.org/10.1016/j.nmd.2015.01.006

60. Binda A, Renna L V., Bosè F, Brigonzi E, Botta A, Valaperta R, et al. SCN4A as modifier gene in patients with myotonic dystrophy type 2. Sci Rep. 2018;8(1):1-10.

61. Bugiardini E, Rivolta I, Binda A, Soriano Caminero A, Cirillo F, Cinti A, et al. SCN4A mutation as modifying factor of Myotonic Dystrophy Type 2 phenotype. Neuromuscul Disord. 2015;

62. Sun C, Van Ghelue M, Tranebjærg L, Thyssen F, Nilssen O, Torbergsen T. Myotonia congenita and myotonic dystrophy in the same family: Coexistence of a CLCN1 mutation and expansion in the CNBP (ZNF9) gene. Clin Genet. 2011;80(6):574-80.

63. Cardani R, Giagnacovo M, Botta A, Rinaldi F, Morgante A, Udd B, et al. Co-segregation of DM2 with a recessive CLCN1 mutation in juvenile onset of myotonic dystrophy type 2. J Neurol. 2012;259(10):2090-9.

64. Cannon SC. Voltage-sensor mutations in channelopathies of skeletal muscle. J Physiol. 2010;588(11):1887-95.

65. Horstick EJ, Linsley JW, Dowling JJ, Hauser MA, McDonald KK, Ashley-Koch A, et al. Stac3 is a component of the excitation-contraction coupling machinery and mutated in Native American myopathy. Nat Commun. 2013;4.

66. Flucher BE, Campiglio M. STAC proteins: The missing link in skeletal muscle EC coupling and new regulators of calcium channel function. Biochim Biophys Acta - Mol Cell Res [Internet]. 2019;1866(7):1101-10. Available from: https://doi.org/10.1016/j.bbamcr.2018.12.004

67. Wu F, Quinonez M, DiFranco M, Cannon SC. Stac3 enhances expression of human CaV1.1 in Xenopus oocytes and reveals gating pore currents in HypoPP mutant channels. J Gen Physiol. 2018;150(3):475-89.

68. Fuster C, Perrot J, Berthier C, Jacquemond V, Charnet P, Allard B. Na leak with gating pore properties in hypokalemic periodic paralysis V876E mutant muscle Ca channel. J Gen Physiol. 2017;149(12):1139-48.

69. Hunter JM, Ahearn ME, Balak CD, Liang WS, Kurdoglu A, Corneveaux JJ, et al. Novel pathogenic variants and genes for myopathies identified by whole exome sequencing. Mol Genet Genomic Med. 2015;3(4):283-301.

70. Ardissone A, Sansone V, Colleoni L, Bernasconi P, Moroni I. Intrafamilial phenotypic variability 
in Andersen-Tawil syndrome: A diagnostic challenge in a potentially treatable condition. Neuromuscul Disord. 2017;

71. Yoon G, Quitania L, Kramer JH, Fu YH, Miller BL, Ptáček L. Andersen-Tawil syndrome: Definition of a neurocognitive phenotype. Neurology. 2006;

72. Nguyen HL, Pieper GH, Wilders R. Andersen-Tawil syndrome: Clinical and molecular aspects. Int J Cardiol [Internet]. 2013;170(1):1-16. Available from: http://dx.doi.org/10.1016/j.ijcard.2013.10.010

73. Veerapandiyan A, Statland JM, Tawil R. Andersen-Tawil Syndrome Summary Diagnosis Suggestive Findings. 2019;1-19.

74. Kokunai $Y$, Nakata T, Furuta M, Sakata S, Kimura H, Aiba T, et al. A Kir3.4 mutation causes Andersen-Tawil syndrome by an inhibitory effect on Kir2.1. Neurology. 2014;82(12):1058-64.

75. Todd JJ, Sagar V, Lawal TA, Allen C, Razaqyar MS, Shelton MS, et al. Correlation of phenotype with genotype and protein structure in RYR1-related disorders. J Neurol [Internet]. 2018;265(11):2506-24. Available from: http://dx.doi.org/10.1007/s00415-018-9033-2

76. Zhou H, Lillis S, Loy RE, Ghassemi F, Rose MR, Norwood F, et al. Multi-minicore disease and atypical periodic paralysis associated with novel mutations in the skeletal muscle ryanodine receptor (RYR1) gene. Neuromuscul Disord [Internet]. 2010;20(3):166-73. Available from: http://dx.doi.org/10.1016/j.nmd.2009.12.005

77. Castañeda MS, Zanoteli E, Scalco RS, Scaramuzzi V, Caldas VM, Reed UC, et al. A novel ATP1A2 mutation in a patient with hypokalaemic periodic paralysis and CNS symptoms. Brain. 2018;141(12):3308-18.

78. Auré K, Dubourg O, Jardel C, Clarysse L, Sternberg D, Fournier E, et al. Episodic weakness due to mitochondrial DNA MT-ATP6/8 mutations. Neurology. 2013;81(21):1810-8.

79. Burge JA, Hanna MG. Novel insights into the pathomechanisms of skeletal muscle channelopathies. Current Neurology and Neuroscience Reports. 2012.

80. Groh WJ. Mexiletine is an effective antimyotonia treatment in myotonic dystrophy type 1. Neurology. 2011;76(4):409.

81. Braude P, Pickering S, Flinter F, Ogilvie CM. Preimplantation genetic diagnosis. Nat Rev Genet. 2002;3(12):941-53. 